\title{
A double-duty food systems stimulus package to build back better nutrition from COVID-19
}

\author{
Emerging evidence indicates that the changes brought about by COVID-19 have raised the risk of unhealthy weight \\ gain, food insecurity and undernutrition. Building back better nutrition demands a double-duty approach where \\ actions to aid recovery synergistically reduce the risk of both obesity and undernutrition.
}

\section{Corinna Hawkes and Charlotte Gallagher Squires}

E merging evidence suggests the economic, social and food system impacts of the COVID-19 pandemic have increased the risk of weight gain in adults and children. Studies from Latin America ${ }^{1}$, Asia $^{2}$, the Middle East ${ }^{3}$, Europe ${ }^{4}$, and North America ${ }^{5}$ have found that around one quarter of adults report gaining weight during lockdown. Compared to their behaviour prior to the lockdown, adults and young people report less healthy eating practices, including increased snacking and higher consumption of foods high in refined carbohydrates, salt, sugar and saturated fats $^{3,6-9}$. Self-reported reasons for these changes include reduced access to healthy foods, having less time to plan healthy meals, difficulties with controlling food intake and using food to cope with low mood or anxiety associated with the pandemic $\mathrm{c}^{6,10,11}$.

It has been reported, too, that some large food companies have been using the COVID-19 lockdowns as an opportunity to make pre-packaged 'ultra-processed' foods high in fats, sugars and salt more appealing ${ }^{12}$. In Mexico, for example, sugary snacks have been promoted with messages that they alleviate boredom, can be eaten during video calls and are supportive of social distancing and health professionals ${ }^{13}$. Reports show that large food companies have donated food boxes containing ultra-processed, branded products to people in need ${ }^{12}$. These reports are especially concerning given people affected by obesity and non-communicable diseases are at greater risk of complications, hospitalization and death from COVID-19 ${ }^{14}$.

At the same time, studies have reported certain population groups cooking meals at home more often and eating more fruit and vegetables 9 . This may reflect a tendency to consume more of all types of foods ${ }^{3}$ and/ or trends playing out differently among socioeconomic groups. For example, Chopra et al. ${ }^{2}$ observed a greater shift toward healthy eating practices among higher socioeconomic groups in India, reasoning this was likely due to this group having more time, resources and capacity to procure and prepare such foods. A shift toward favourable dietary practices in France was more common among those on a higher-income, working from home and without dependent children ${ }^{7}$. Those whose work habits have been unchanged by the pandemic are less likely to report any changes to their dietary practices ${ }^{7,10}$.

\section{Concomitant growth of undernutrition and food insecurity}

The economic crisis brought about by COVID-19 has also led to increased food insecurity among lower-income households across countries, as shown by the examples of Mexico ${ }^{15}$, Bangladesh ${ }^{16}$ and Ethiopia ${ }^{17}$. In Addis Ababa, Ethiopia, spending less on food was the second most commonly reported means of coping with income loss associated with the pandemic ${ }^{17}$. Adolescents in Côte d'Ivoire report skipping meals to cope with income losses associated with the pandemic ${ }^{18}$. In South Africa, $41 \%$ of families in a nationally representative panel survey reported running out of money for food and $16 \%$ that their children had gone hungry the previous week ${ }^{19}$. Likewise, growing levels of food insecurity have been found in high-income countries including the $\mathrm{UK}^{20}$, USA ${ }^{21}$ and Australia ${ }^{22}$. This has also been associated with eating cheaper and less healthy foods. In Brazil, for example, families with drastic or total loss of income report eating cheaper foods to cope $\mathrm{e}^{23}$ and food insecurity resulting from COVID-19 in Australia is associated with consuming less fresh foods ${ }^{22}$. Modelling simulations suggest that COVID-19 will exacerbate undernutrition, with additional deaths due to child wasting and stunting and increased anaemia among women ${ }^{24,25}$.

\section{Tackling malnutrition in all its forms through food systems}

Eating practices are shaped by the circumstances of everyday life and
COVID-19 changed those circumstances for many, giving rise to risks for both obesity and undernutrition. This creates an imperative for a response that takes a holistic approach to considering obesity and undernutrition in the same frame if the world is to build back better nutrition in the wake of COVID-19.

There have been multiple responses to the economic, social and food-systems impacts of COVID-19. International entities and governments have provided large stimulus packages and national governments have allocated budgetary resources to social safety nets for households experiencing loss of income, in part to protect against food insecurity and undernutrition. According to the World Bank, 173 countries had enacted 621 new social protection measures by June 2020, including cash transfers and in-kind food and voucher schemes ${ }^{26}$.

However, national budgets are under tremendous strain and the full impact of COVID-19 on existing programmes designed to tackle undernutrition remains unclear. Despite the evidence on the link with COVID-19, the World Obesity Federation reports that governments around the world are paying inadequate attention to obesity prevention and management ${ }^{27}$.

At the same time, there has been significant social, community and business innovation across low-, middle- and high-income countries to provide and sell nutritious, healthy foods. Examples include novel programmes to distribute seeds for home gardens, new forms of transportation networks to get perishable foods to markets, e-commerce, innovations in sales channels from urban agriculture, and community kitchens ${ }^{28}$. The impacts of COVID-19 on food systems globally, nationally and locally has also led to greater attention on how to improve their resilience and maximize their potential to improve a range of different outcomes, as articulated in the UN Food Systems Summit to be held in September 2021. 
Double-duty actions for double burden. In this context, double-duty actions emerge as one way to step up the food system response to risks of food insecurity, undernutrition and obesity. Double-duty actions are interventions, programmes and policies that simultaneously prevent or reduce the risk of both nutritional deficiencies leading to underweight, wasting, stunting and micronutrient deficiencies, and problems of obesity, and diet-related non-communicable diseases ${ }^{29}$. They offer an effective way to address malnutrition in all its forms; with action targeting one form of nutrition also working to benefit another. Given the evidence of increasing undernutrition and obesity in the wake of the COVID-19 pandemic, paired with renewed attention on food systems, now is the time for a clear package to stimulate food systems to work double duty and address all forms of malnutrition.

Social protection and subsidy programmes targeting low-income groups. Spending on social safety nets has increased during COVID-19. While social protection programmes are proven to have positive outcomes for nutrition, evidence suggests that they are not designed to take into account the cost of nutritious foods nor the increasingly obesogenic nature of food systems $^{29}$. More could be done to leverage them to incentivize food systems actors to make healthier foods more available and affordable. Cash provision could be coupled with incentives for recipients to participate in well-targeted, culturally sensitive food literacy programmes based on an understanding of barriers to consumption of nutritious foods. Subsidies and food vouchers could also be directly linked to retailers providing nutritious foods, provide rewards for expenditure on healthier foods, and exclude foods, snacks, and beverages high in fats, sugars and salt thus stimulating retailers to change their food offer. In addition, public distribution programmes, state-managed stores, public restaurants, and other forms of subsidy programmes could focus on providing diverse nutritious foods and meals and minimizing less-healthy foods. Likewise, mandatory guidance is needed for voluntary food donations from food companies to vulnerable groups to stimulate them to provide only food that will actively address malnutrition in all its forms ${ }^{30}$.

Comprehensive school food policies. According to the World Food Programme, 161 countries closed schools during lockdowns, leaving 346 million children without access to school feeding programmes $^{31}$. Their re-opening presents an opportunity to ensure that guidelines for school feeding programmes and food provided by the commercial sector in day care, preschools, and schools act double duty by meeting basic energy and nutrient needs and restricting nutrient-poor yet calorie-rich foods, snacks, and beverages. This also presents an opportunity to prioritize procurement from farmers and other producers and retailers of nutritious foods, providing structured demand to stimulate job generation in the nutritious foods sector. For a full double-duty approach, the widespread availability of snacks and fried foods around schools should be replaced with more nutritious foods and schools used as an opportunity to build knowledge and skills to create awareness, shape tastes, and motivate consumption of healthy diets through education, school gardens, and mainstreaming food throughout the curriculum.

\section{Food system financing.}

Government-financed economic stimulus packages in the wake of COVID-19 present an opportunity to allocate new investment to nutritious foods as a boost to employment, such as stimulating agri-food entrepreneurship, providing credit on fair terms to family farmers, investing in cooperatives and food hubs for distribution of healthy foods, providing financing for small- and medium-sized enterprises (SMEs) to innovate new nutritious products, and providing technical and financial support to street vendors to switch to healthier offers. These investments could build on the aforementioned innovations during COVID-19 lockdowns. For example, SME e-commerce initiatives are growing in the wake of COVID-19 in many lower-income countries and could be provided with marketing support to boost demand for healthier foods (it is notable that e-commerce initiatives by some large companies during COVID-19 are reported to have not focused on improving access to nutritious healthy foods ${ }^{30}$ ). At the same time, existing public- and private-sector investment could be re-allocated from refined starchy foods and ingredients used in 'ultra-processed' snacks and convenience foods toward nutritious foods. Global food and agriculture investments are reported to have tripled between 2004-2013 to more than US $\$ 100$ billion (ref. ${ }^{32}$ ); and the number of investment funds specialized in food and agriculture increased from 38 to 446 between $2005-2017^{33}$. The potential for focusing such investments on the production, storage, distribution, processing and retail of nutritious foods rather than ingredients used in unhealthy products is enormous, supporting livelihoods while also supplying healthier foods at more affordable prices. Agricultural subsidies, infrastructure and research investments could also be re-allocated to more nutritious foods ${ }^{34}$, as could public procurement spend.

Taxes and marketing restrictions. The disruption to economic systems and stretched government budgets as a result of the pandemic makes this an optimal time to consider implementing policies on taxation of sugary drinks as a means of adding fiscal space to constrained national economies and stimulating new resources for interventions to address all forms of malnutrition. Over 42 countries have now adopted sugary drinks taxes and evidence shows they have the intended effects ${ }^{35}$. Existing sugary drinks taxes could be increased and new taxes introduced to not just provide revenue but also stimulate sugar reduction by the companies who produce them and stimulate consumers to switch to healthier drinks. Tougher regulation is also needed to reign in marketing of unhealthy foods so prevalent during the pandemic ${ }^{27}$. This could stimulate businesses to find ways to generate aspiration for nutritious foods that benefit all forms of malnutrition, and to compete to a greater degree on growing long-term markets for healthier foods rather than focusing on pre-packaged foods high in fats, sugars and salt and ultra-processed snacks and drinks.

\section{A window of opportunity}

In the context of the link between obesity and COVID-19, the estimated increases of undernutrition, and the changes in food systems, a window of opportunity has opened to stimulate change in food systems through double-duty action to address malnutrition in all its forms. We propose a short but potentially powerful package of actions to effect change - what is now required is the political commitment to put it into action.

\section{Corinna Hawkes (iD) ${ }^{m}$ and}

Charlotte Gallagher Squires

Centre for Food Policy, City, University of London,

London, UK.

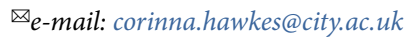

Published online: 21 April 2021

https://doi.org/10.1038/s43016-021-00260-6

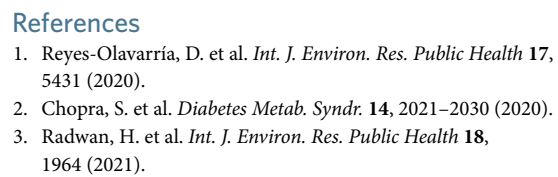


4. Fernandez-Rio, J., Cecchini, J. A., Mendez-Gimenez, A. \& Carriedo, A. Obes. Res. Clin. Pract. 14, 383-385 (2020).

5. Zachary, Z. et al. Obes. Res. Clin. Pract. 14, 210-216 (2020).

6. Ammar, A. et al. Nutrients 12, 1583 (2020).

7. Deschasaux-Tanguy, M. et al. Am. J. Clin. Nutr. https://doi. org/10.1093/ajcn/nqaa336 (2021).

8. Ruiz-Roso, M. B. et al. Nutrients 12, 1807 (2020).

9. Zupo, R. et al. Int. J. Environ. Res. Public Health 17, 7073 (2020).

10. Di Renzo, L. et al. Nutrients 12, 2152 (2020).

11. Robinson, E. et al. Appetite 156, 104853 (2021).

12. Signalling Virtue, Promoting Harm: Unhealthy Commodity Industries and COVID-19 (NCD Alliance, SPECTRUM, 2020).

13. White, M., Nieto, C. \& Barquera, S. Obesity 28, 1578-1579 (2020).

14. Popkin, B. M. et al. Obes. Rev. 21, e13128 (2020).

15. Gaitán-Rossi, P., Vilar-Compte, M., Teruel, G. \& Pérez-Escamilla, R. Public Health Nutr. 24, 412-421 (2020).

16. Hamadani, J. D. et al. Lancet Glob. Health 8, e1380-e1389 (2020).

17. Abate, G. T., de Brauw, A. \& Hirvonen, K. Food and Nutrition Security in Addis Ababa, Ethiopia during COVID-19 Pandemic: June 2020 Report (IFPRI, 2020).

18. Banati, P., Jones, N. \& Youssef, S. Eur. J. Dev. Res. 32, 1613-1638 (2020).

19. Van der Berg, S., Patel, L. \& Bridgman, G. Hunger in South Africa during 2020: Results from Wave 3 of NIDS-CRAM (NIDS, CRAM, 2021).

20. Loopstra, R. Vulnerability to Food Insecurity since the COVID-19 Lockdown (Food Foundation, 2020).
21. Wolfson, J. A. \& Leung, C. W. Nutrients 12, 1648 (2020).

22. Kent, K. et al. Nutrients 12, 2682 (2020).

23. Campagnaro, R. et al. Child. Youth Serv. Rev. 118, 105469 (2020).

24. Headey, D. et al. Lancet 396, 519-521 (2020).

25. Osendarp, S. et al. Preprint at Research Square https://doi. org/10.21203/rs.3.rs-123716/v1 (2020).

26. Gentilini, U. et al. Social Protection and Jobs Responses to COVID-19: A Real-Time Review of Country Measures (World Bank, 2020).

27. Obesity and COVID-19: Policy Briefing (World Obesity Federation, 2020)

28. Hawkes, C. in COVID-19 and Global Food Security (eds Swinnen, J. \& McDermott, J.) 129-131 (IFPRI, 2020).

29. Hawkes, C., Ruel, M. T., Salm, L., Sinclair, B. \& Branca, F. Lancet 395, 142-155 (2020)

30. Nutrition Responses from Food and Beverage Companies to the Covid-19 Pandemic: Report 2: An Acute Response (ATNI, 2020)

31. Global Monitoring of School Meals During COVID-19 Schoo Closures (World Food Programme, 2021); https://cdn.wfp. org/2020/school-feeding-map/index.html

32. Goedde, L., Horii, M. \& Sanghvi, S. Global Agriculture's Many Opportunities (McKinsey, 2015).

33. 2018 Global Food \& Agriculture Investment Outlook (Valoral Advisors, 2018).
34. Future Food Systems: For People, Our Planet, and Prosperity (Global Panel on Agriculture and Food Systems for Nutrition, 2020).

35. Shekar, M. \& Popkin, B. (eds) Obesity: Health and Economic Consequences of an Impending Global Challenge (World Bank Group, 2020).

Acknowledgements

The authors thank M. Shekar and S. Osendarp for their comments on an earlier iteration of the text.

Author contributions

C.H. planned, structured and wrote the text. C.G.S.

conducted and wrote the literature review and edited the text.

Competing interests

The authors declare no competing interests.

Additional information

Peer review information Nature Food thanks Angela Jackson-Morris and Johanna Ralston for their contribution to the peer review of this work. 